\title{
Design and analysis of frequency reconfigurable antenna for global positioning system applications
}

\author{
Najim Abdallah Jazea1, Ali Khalid Jassim², Alaa Kareem Hassan² \\ ${ }^{1}$ Department of Computer Techniques Engineering, Alhikma University College, Baghdad, Iraq \\ ${ }^{2}$ Department of Electrical engineering, College of Engineering, Mustansiriyah University, Baghdad, Iraq
}

\begin{tabular}{l} 
Article Info \\
\hline Article history: \\
Received Oct 7, 2021 \\
Revised Dec 10, 2021 \\
Accepted Jan 6, 2022 \\
\hline
\end{tabular}

Keywords:

Global positioning system

PIN diode

Reconfigurable antenna

Worldwide interoperability for

microwave access

Wireless local area network

\begin{abstract}
A compact frequency reconfigurable antenna is designed and analyzed in this paper to operate with global positioning system (GPS) and worldwide interoperability for microwave access (WiMAX) applications. The designed antenna is printed on flame resistant 4 (FR4) epoxy substrate with relative permittivity is 4.3 , loss tangent of 0.03 and overall substrate with ground (GND) plane dimensions of $(54.6 \times 54.6 \times 1.6) \mathrm{mm}^{3}$ and patch dimensions of $(45 \times 45) \mathrm{mm}^{2}$. The antenna is designed and optimized using computer simulation technology (CST) package through series of parametric studies in order to cover the GPS, WiMAX bands with resonant frequency of 1.229 $\mathrm{GHz}, 1.575 \mathrm{GHz}$, and $3.34 \mathrm{GHz}$. Two triangular slots at the patch sides and single elliptical slot at the middle are etched for the best antenna performance. The designed antenna performs frequency re-configurability by using PIN diode switch at the inset feed to change the operating frequencies from double band operation at (1.575 and 3.34) $\mathrm{GHz}$ to single band at $1.229 \mathrm{GHz}$ under $\mathrm{S} 11 \leq-10 \mathrm{~dB}$. The proposed antenna produces accepted simulation results with voltage standing wave ratio (VSWR), maximum radiation efficiency and gain of less than $2.76 \%$ and $7.035 \mathrm{dBi}$ respectively.
\end{abstract}

This is an open access article under the CC BY-SA license.

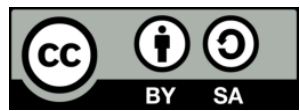

\section{Corresponding Author:}

Najim Abdallah Jazea

Department of Computer Techniques Engineering, Alhikma University College

Uqba Bin Nafeh Square, Karada Kharidge, Baghdad, Iraq

Email: najim.abdulah@ @iuc.edu.iq

\section{INTRODUCTION}

The global positioning system (GPS) system requires only a receiver for the wireless signal received from a satellite (one-way transmission from satellites to users) in order to determine the location (latitude, longitude, altitude, and time) depends on 24 satellite constellations that every six satellites in each orbit that circle the earth in near-circular inclined orbits. The GPS system is used for commercial navigation and land systems. The GPS operates on the L-band microwave frequencies from 1-2 GHz [1]. The GPS receiver operates at two frequencies $(\mathrm{L} 1=1.575 \mathrm{GHz}$ and $\mathrm{L} 2=1.227 \mathrm{GHz}$ ). In the GPS receiver, the receiving antenna requires high performance of radiation pattern matching and impedance, high regression ratio for cross polarization and right circular polarization because the received signals are very weak. Two points must be taken into account in order to design an antenna that meets these requirements or specifications, the first is to use a multi-channel GPS receiver, while the other point is that the designed antenna must meet all the above specifications in order to allow independent sectoral coverage of the required hemispherical radiation pattern so that it reduces antenna requirements at the expense of a more complex circuit and a larger number of antennas [2].

In the past two decades, due to its compressibility, among other advantages, the microstrip patch antenna has been widely used in synthetic aperture radar applications and personal communications systems. 
Extensive research has been carried out to develop new technologies to overcome the disadvantages of microstrip antennas, the narrowest of which is the microstrip. Optimizing return loss and bandwidth without affecting the manufacturing process and increasing antenna size is important for its application to modern mobile communication systems. The microstrip antenna has many preferred characteristics such as light weight, low profile and low cost of integrating with wireless communication system, GPS, mobile applications wireless local area network (WLAN), worldwide interoperability for microwave access (WiMAX), and long term evolution (LTE), radar systems and satellite communication systems [3]. The reconfigurable antennas recently have been received great attention in wireless communication systems by researchers due to their capabilities for maintaining various functionalities of multiple frequencies, multiple patterns, and multiple polarizations re-configurability. In addition the reconfigurable antennas are used to reduce the number of antennas through utilizing single reconfigurable antenna instead of multiple multi-band antenna with better characteristics [4], [5]. In another hand, the reconfigurable antenna has the ability to reduce the filter requirement at the front-end system by providing the interference signals rejection for the unused bands [6].

There are a lot of reconfigurable antennas proposed to operate with different wireless communication systems such as in [4], a circular disc-shaped reconfigurable antenna with beam steering the radiation pattern for GPS applications using three PIN diode. For mobile applications, a foldable reconfigurable indoor loop antenna is designed which can operate in the heptad range, including GPS, global system for mobile (GSM850), GSM900, PCS, digital cellular system (DCS), WLAN, and universal mobile telecommunications system (UMTS) with return loss less than $6 \mathrm{dBm}$ [7]. At $1.57 \mathrm{GHz}$ and $2.33 \mathrm{GHz}$ or satellite digital audio radio (SDAR), a reconfigurable monopole antenna with switchable frequency and circular polarization is designed for GPS applications [8]. For frequencies from $1.9 \mathrm{GHz}$ to $2.4 \mathrm{GHz}$ for $\mathrm{S} 11$ wireless applications below $-6 \mathrm{~dB}$ using a PIN diode a small reconfigurable ribbon patch antenna was introduced as Yagi Uda [6]. A reconfigurable multi-band inverted antenna (PIFA) operating in wireless fidelity (WiFi), GPS, GSM, third generation (3G), 4 UMTS, and LTE applications using PIN diodes has been proposed [9]. It has been suggested for hexaband mobile wireless and X-bands applications such as WLAN at $5.5 \mathrm{GHz}$, WiFi at $2.402 \mathrm{GHz}$, GPS at $1.56 \mathrm{GHz}, \mathrm{X}$-bands at $10.7 \mathrm{GHz}$, and WIMAX at $3.48 \mathrm{GHz}, 7.3 \mathrm{GHz}$ [10]. The frequency for tablet computers and reconfigurable multi user, multiple input, multiple output (MIMO) wireless terminals is presented eg wireless wide area network (WWAN)/LTE/global navigation satellite system (GLONASS)/GPS/GSM using PIN diodes. The proposed antenna covers the GLONASS/GSM850/900/GPS and LTE2300/2500/3400 in the off state while supporting DCS/PCS/UMTS frequency bands in the PIN diode ON state [11].

In this paper, a frequency reconfigurable microstrip antenna is proposed and designed to cover the GPS and WLAN or WiMAX frequencies through using PIN diode for frequency tuning. The contributions behind this research are summarized as shown intion: design and analysis a new compact frequency reconfigurable antenna structure for GPS applications with overall dimensions of substrate and GND plane dimensions of $(54.6 \times 54.6 \times 1.6) \mathrm{mm}^{3}$ and patch dimensions of $(45 \times 45) \mathrm{mm}^{2}$. The antenna operates with three resonant frequencies using single PIN diode at the inset feed with (1.575 and 3.34) $\mathrm{GHz}$ and $1.229 \mathrm{GHz}$ for both $\mathrm{ON}$ and OFF states of the PIN diode under $\mathrm{S} 11 \leq-10 \mathrm{~dB}$ with maximum gain of $7.7 \mathrm{dBi}$.

\section{THE ANTENNA DESIGN CONSIDERATION}

The proposed frequency reconfigurable antenna is designed using CST using "(1)" to "(5)" [13], [14] with front and back sides shown in Figure 1(a). Designed antenna using square FR4 substrate with loss tangent of $0.002,1.6 \mathrm{~mm}$ thickness and overall dimensions of substrate and GND plane dimensions of (58.1x58.1x1.6) $\mathrm{mm}^{3}$, patch dimensions of $(48.5 \times 48.5) \mathrm{mm}^{2}$, and $50 \Omega$ micro strip line feed.

$$
\begin{aligned}
& W=\frac{V_{0}}{2 f_{r}} \sqrt{\frac{2}{\varepsilon_{r}+1}} \\
& \varepsilon_{r e f f}=\frac{\varepsilon_{r}+1}{2}+\frac{\varepsilon_{r}-1}{2}\left[1+12 \frac{h}{w}\right]^{-\frac{1}{2}} \\
& \Delta L=0.412 \mathrm{~h} \frac{\left(\varepsilon_{r e f f}+0.3\right)\left(\frac{w}{h}+0.264\right)}{\left(\varepsilon_{r e f f}-0.258\right)\left(\frac{w}{h}+0.8\right)} \\
& L_{e f f}=L+2 \Delta L \\
& L=\frac{V_{0}}{2 f_{r} \varepsilon_{r e f f}}-2 \Delta L
\end{aligned}
$$

Where, $\mathrm{W}$ is the patch width, $\varepsilon_{\mathrm{r}}$ : the dielectric constant $\mathrm{V}_{\mathrm{o}}$ is velocity of light, $\varepsilon_{\text {reff }}$ is the effective dielectric constant, fr is the resonant frequency, $\Delta \mathrm{L}$ is the length, $\mathrm{h}$ is the substrate height, $\mathrm{L}$ is the actual patch length, $\mathrm{L}_{\text {eff }}$ is the effect patch. 
After that an inset feed length is designed using “(6)" [17] with length of (Lgap=18.23 mm and $\mathrm{Wgap}=1 \mathrm{~mm}$ ) is produced for impedance matching enhancement as presented in Figure 1(b).

$$
R_{i}\left(y=y_{0}\right)=R(y=0) \cos ^{2}\left(\frac{\pi y_{0}}{L}\right)
$$

Where, $R_{i}\left(y=y_{0}\right) \sim 50 \Omega$ : is desired input impedance, $R_{i}(y=0) \sim 530 \Omega$ : is the resistance of the patch antenna, $y_{0}$ : is the inset length which is equal to Lgap, $L$ : is the patch length.

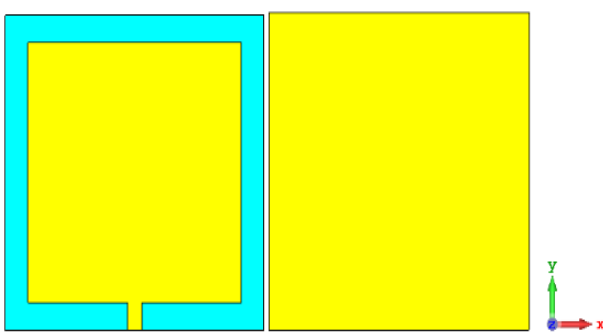

(a)

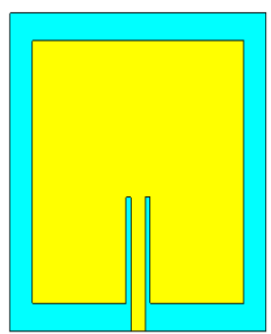

(b)

Figure 1. The proposed microstrip antenna structure (a) without inset feed and (b) with inset feed

An elliptical slot at the patch center is produced to obtain the double band with $\mathrm{S} 11 \leq-10 \mathrm{~dB}$ at 1.5 $\mathrm{GHz}$ and $3.25 \mathrm{GHz}$ as shown in Figure 2(a) and cancelling the $4.5 \mathrm{GHz}$. The elliptical slot is designed with optimum radii of $(\mathrm{Ru}=6 \mathrm{~mm}$ and $\mathrm{Rv}=3.5 \mathrm{~mm})$ through using parametric study as presented in Figure 2(b) and Figure 2(c). After that the patch dimensions ( $\mathrm{L}$ and $\mathrm{W})$ are optimized through several parametric studies in order to maintain the GPS band so that the optimum patch dimensions are $\left(45 \times 45 \mathrm{~mm}^{2}\right)$ as shown in Figure 3 . In Table 1, the overall optimum dimensions of the antenna are summarized.

The electrical technique for achieving frequency configurability is used, through using RF PIN diode as electronic switch for frequency tuning. The proposed antenna with PIN diode model is shown in Figure 4, which produces the on-state and off-state [13], [14].

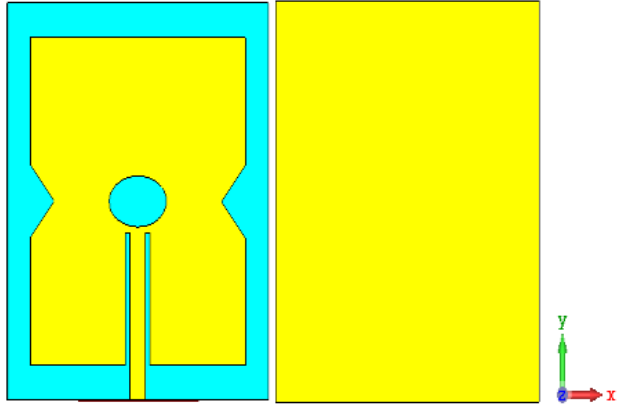

(a)

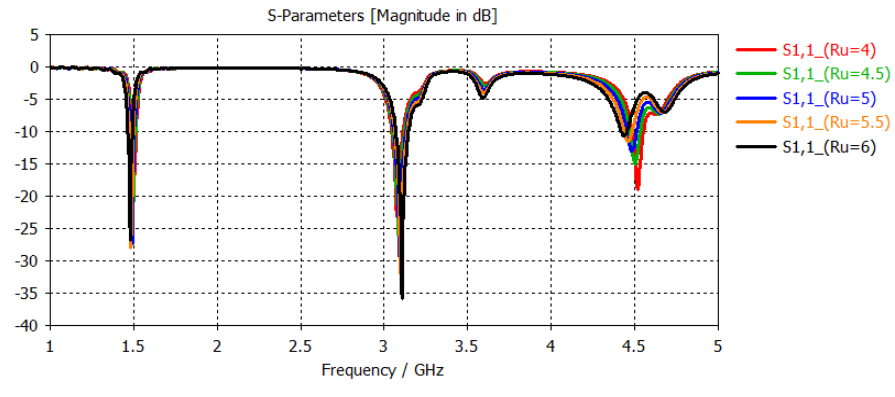

(b)
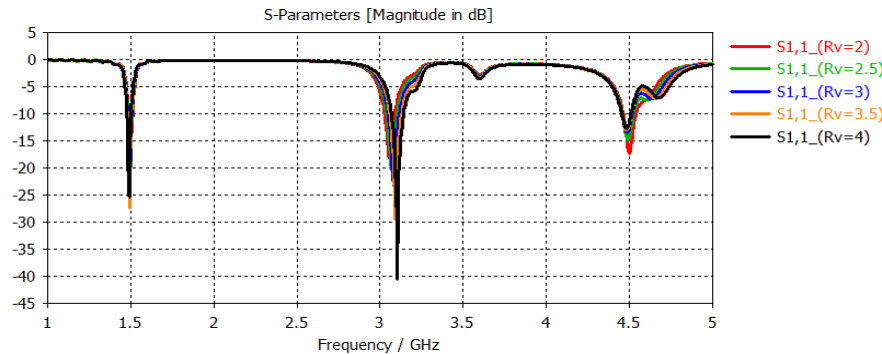

(c)

Figure 2. The parametric study of using elliptical slots with; (a) the proposed antenna with elliptical slot, (b) $\mathrm{Ru}=6 \mathrm{~mm}$, and (c) $\mathrm{Rv}=3.5 \mathrm{~mm}$ 
Table 1. Optimum dimension's parameters

\begin{tabular}{cccc}
\hline Parameter & Value $(\mathrm{mm})$ & Parameter & Value $(\mathrm{mm})$ \\
\hline $\mathrm{L}_{\mathrm{g}}$ & 54.6 & $\mathrm{~W}$ & 45 \\
$\mathrm{~W}_{\mathrm{g}}$ & 54.6 & $\mathrm{~L}_{\text {gap }}$ & 18.23 \\
$\mathrm{~L}$ & 45 & $\mathrm{~W}_{\text {gap }}$ & 1 \\
$\mathrm{R}_{\mathrm{u}}$ & 6 & $\mathrm{R}_{\mathrm{v}}$ & 3.5 \\
$\mathrm{a}$ & 5 & $\mathrm{~h}$ & 1.6 \\
$\mathrm{t}$ & 0.035 & &
\end{tabular}

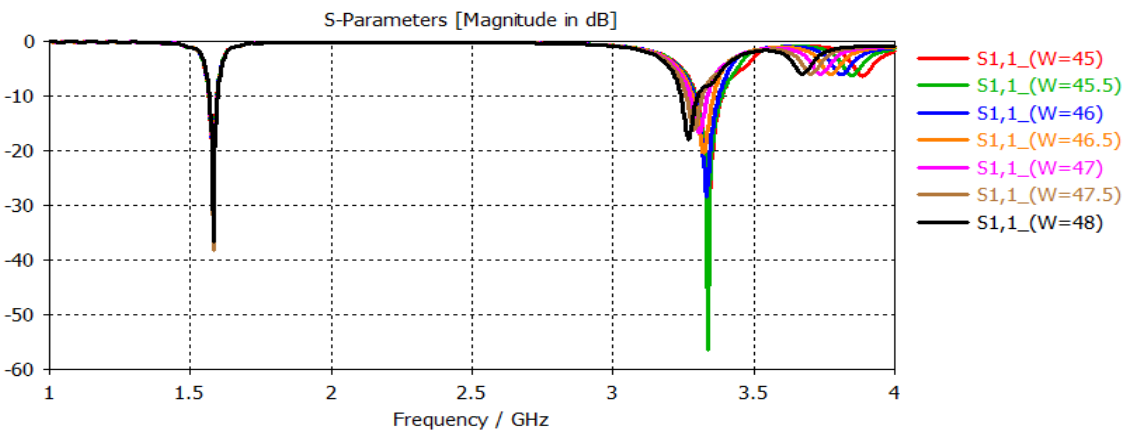

(a)

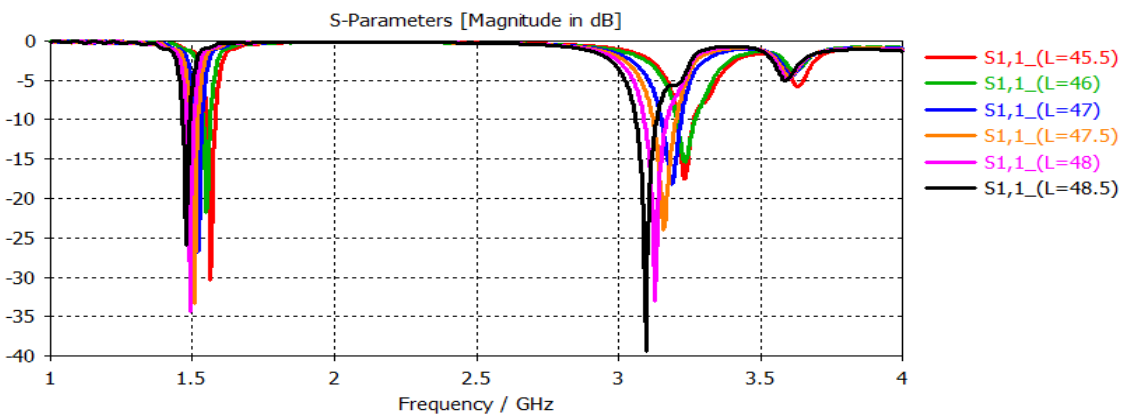

(b)

Figure 3. The parametric study of patch dimensions with (a) width dimensions $\mathrm{W}=45 \mathrm{~mm}$ and (b) length dimensions $\mathrm{L}=45 \mathrm{~mm}$

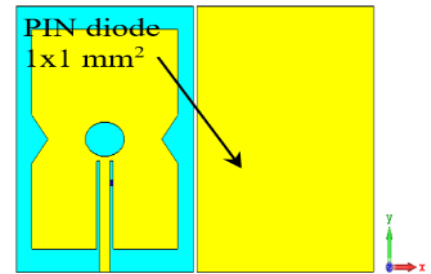

(a) PIN diode

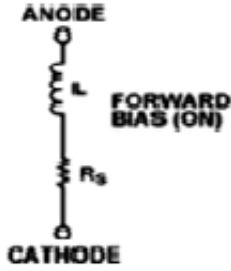

(b) on-state

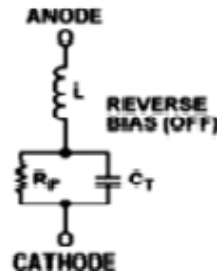

(c) off-state

Figure 4. Designed antenna with, (a) PIN diode modelling, (b) on-state, and (c) off-state

\section{RESULTS AND DISCUSSION}

The simulation results are obtained using CST package after making the parametric study and getting the optimum dimensions as shown in Table 1. Figure 5(a) shows the input reflection coefficient in relation with frequency, the antenna produces three resonant frequencies for the PIN diode. There are double band at the off-state of 1.57 and $3.34 \mathrm{GHz}$, while only single band at the on-state of $1.229 \mathrm{GHz}$ under S11 $\leq-10 \mathrm{~dB}$, they are used for GPS (L1 and L2) and WiMAX applications. The proposed antenna operates VSWR, maximum radiation efficiency and maximum gain of less than $2.76 \%$ and $7.035 \mathrm{dBi}$ respectively. Figure 5(b) presents the relation between gain and frequency. The surface current distribution and radiation pattern at $1.575 \mathrm{GHz}$ can be shown in Figures 6(a) and 6(b) respectively. 


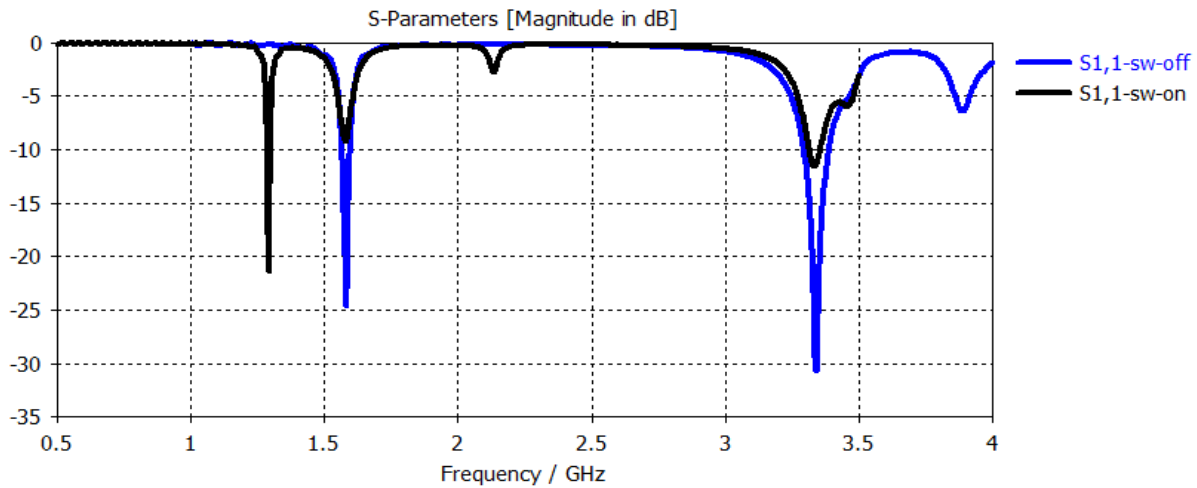

(a)

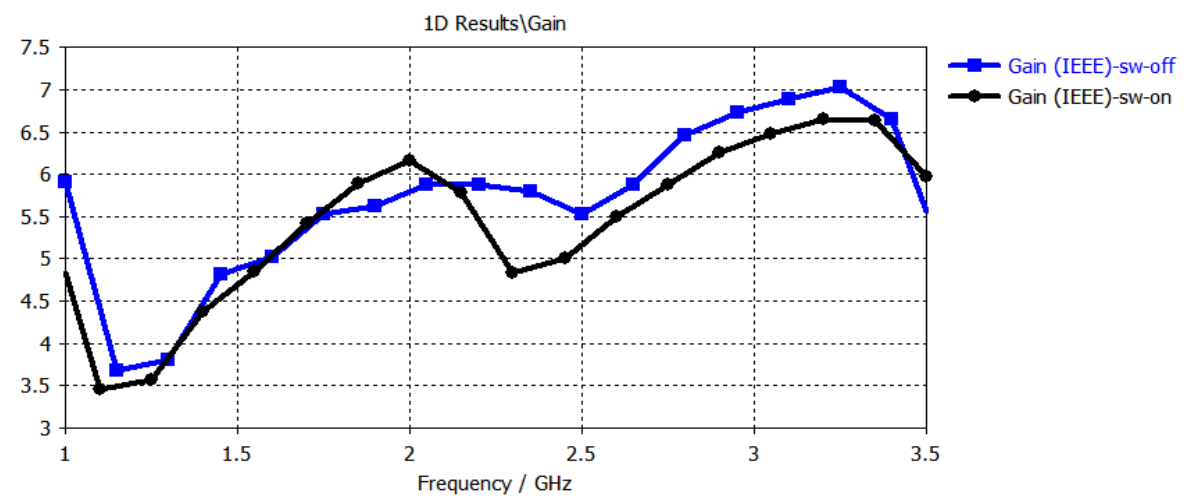

(b)

Figure 5. Designed antenna with (a) S11 input reflection coffecient and (b) simulated gain

The proposed antenna simulation results are compared with other references as presented in table. The simulation results are discussed is being as: As shown in Figure 5(a) the S11 under -20 dB at all resonant frequencies, this means accepted impedance matching. The proposed antenna operates with maximum radiation efficiency of $76 \%$, its accepted performance for wireless radiation. As presented in Figure 5(b) the antenna produces simulation gain from (3.5-7.035) dBi which is accepted for GPS applications. In Figure 6 suggested antenna operates with approximately omnidirectional radiation pattern such that it's important for GPS applications. As presented in Figure 7 the proposed antenna shows it's surface current distribution for both PIN diode cases such that the on-state case at Figure 7(b) present different current distribution when the PIN diode is $\mathrm{ON}$ and as a result the resonant frequency is changed. Table 2. The comparison of the proposed antenna with other references
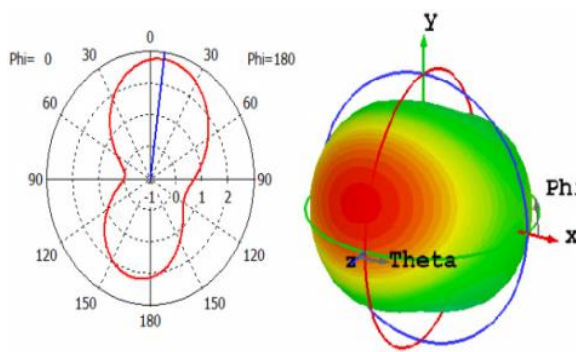

(a)

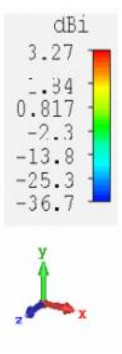

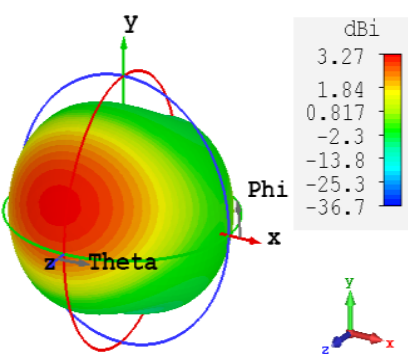

(b)

Figure 6. 2D and 3D radiation pattern at (a) E-plane at $\mathrm{F}_{\mathrm{r}}=1.229 \mathrm{GHz}$ and (b) $\mathrm{H}$-plane at $\mathrm{F}_{\mathrm{r}}=1.229 \mathrm{GHz}$ 

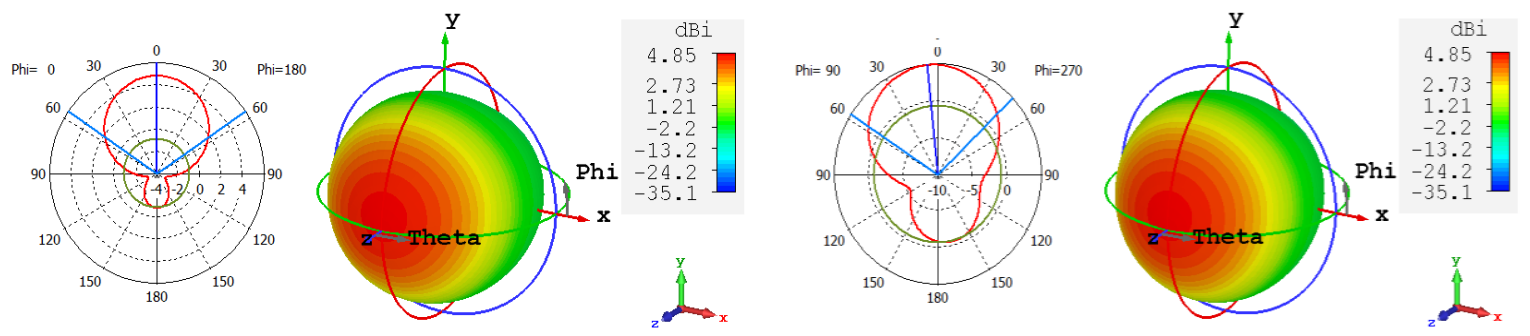

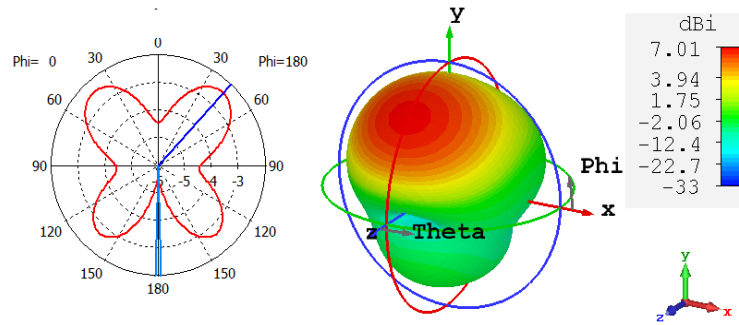

(c) E-plane
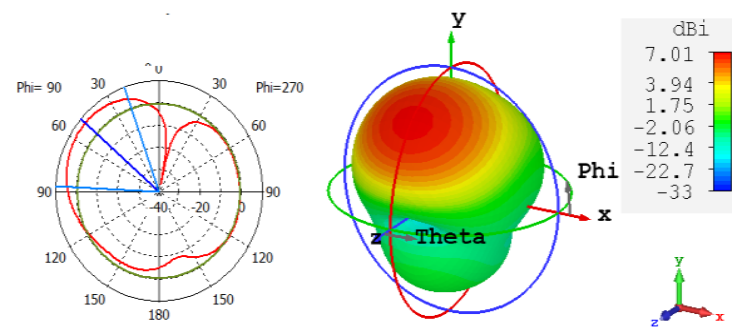

(d) H-plane

Figure 6. 2D and 3D radiation pattern at (c) E-plane at $\mathrm{F}_{\mathrm{r}}=1.575 \mathrm{GHz}$ and $\mathrm{F}_{\mathrm{r}}=3.335 \mathrm{GHz}$ and (d) $\mathrm{H}$-plane at $\mathrm{F}_{\mathrm{r}}=1.575 \mathrm{GHz}$ and $\mathrm{F}_{\mathrm{r}}=3.335 \mathrm{GHz}$ (continue)

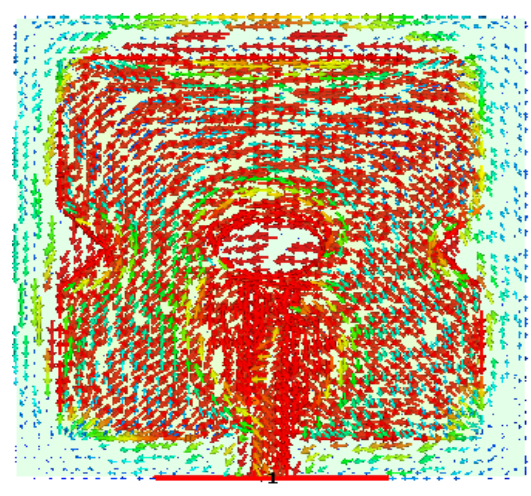

(a)

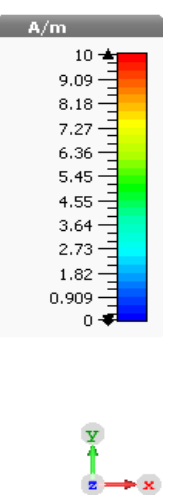

$z \rightarrow x$ (b)

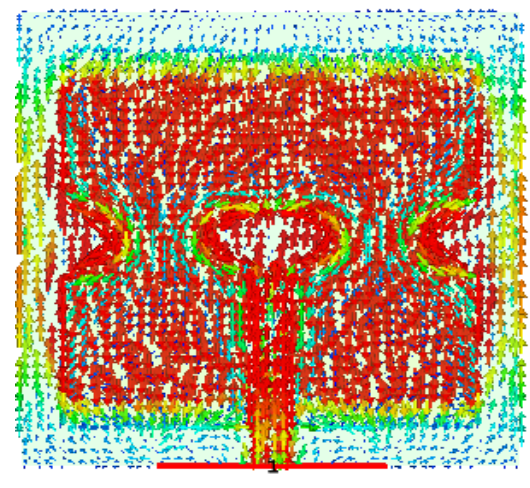

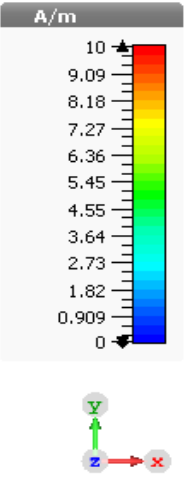

$z \rightarrow x$

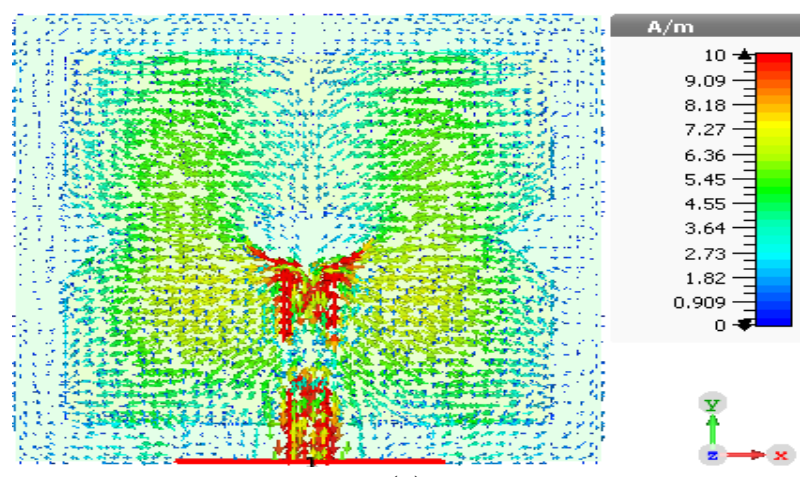

(c)

Figure 7. The antenna surface current distribution at, (a) $\mathrm{F}_{\mathrm{r}}=1.229 \mathrm{GHz}$, (b) $\mathrm{F}_{\mathrm{r}}=1.575 \mathrm{GHz}$, and (c) $\mathrm{F}_{\mathrm{r}}=3.335$ $\mathrm{GHz}$ 
Table 2. The comparison of the proposed antenna with other references

\begin{tabular}{|c|c|c|c|c|c|c|}
\hline \multirow[t]{2}{*}{ References } & \multicolumn{2}{|c|}{$\begin{array}{l}\text { Antenna dimensions } \\
\qquad\left(\mathrm{mm}^{2}\right)\end{array}$} & \multirow[t]{2}{*}{$\begin{array}{l}\text { No. and type } \\
\text { of switches }\end{array}$} & \multirow[t]{2}{*}{$\begin{array}{c}\text { Resonant frequencies } \\
(\mathrm{GHz})\end{array}$} & \multirow[t]{2}{*}{$\begin{array}{l}\text { Peak gain } \\
\quad(\mathrm{dB})\end{array}$} & \multirow[t]{2}{*}{ Applications } \\
\hline & GND & Patch & & & & \\
\hline [4] & $63 \times 63$ & $\mathrm{R}=30$ & 3-PIN & $1.52,1.576$ & 1.456 & GPS \\
\hline [7] & $100 \times 60$ & $60 \times 5$ & 2-PIN & $\begin{array}{c}0.770-0.885,1.520- \\
1.660,2.260-2.560 \\
0.875-1.0101 .7052 .410\end{array}$ & 1.5 & $\begin{array}{l}\text { GSM850, GSM900, } \\
\text { GPS, DCS, PCS, UMTS, } \\
\text { and WLAN }\end{array}$ \\
\hline [8] & $75 \times 45$ & $40 \times 60$ & 2-PIN & $1.57,2.33$ & 2.4 & GPS, SDAR \\
\hline [9] & $60 \times 25$ & $25 \times 15$ & 2-PIN & $\begin{array}{c}0.850,1.57,1.9,2.4,3.8 \\
5.5\end{array}$ & 4 & $\begin{array}{l}\text { GPS, 3G, Wi-Fi, GSM and } \\
4 \mathrm{G} \text { (UMTS and LTE) }\end{array}$ \\
\hline [10] & $56 \times 44$ & $48 \times 18$ & 2-PIN & $\begin{array}{c}5.5,1.56,2.4,3.48,7.3 \\
10.7\end{array}$ & 4.696 & $\begin{array}{l}\text { WLAN, GPS, } \\
\text { WIFI, WIMAX, xbands }\end{array}$ \\
\hline [11] & $150 \times 200$ & $61.5 \times 40.5$ & 1-PIN & $\begin{array}{c}0.9,1.8,1.9,2.3,2.5 \\
3.4,3.55\end{array}$ & ----- & $\begin{array}{l}\text { GSM850/900, } \\
\text { GPS/GLONASS, } \\
\text { LTE2300/2500/3400, } \\
\text { DCS/PCS/UMTS }\end{array}$ \\
\hline Proposed antenna & $54.6 \times 54.6$ & $45 \times 45$ & 1-PIN & $1.29,1.575,3.34$ & 7.035 & GPS, WiMAX \\
\hline
\end{tabular}

\section{CONCLUSION}

In this paper, new structure of frequency reconfigurable antenna to GPS and WiMAX applications. The proposed antenna covers the two bands at frequencies $(\mathrm{L} 1=1.227 \mathrm{GHz}$ and $\mathrm{L} 2=1.575 \mathrm{GHz})$ of the GPS receiver in addition to the $3.5 \mathrm{GHz}$ WiMAX through the two PIN diode states. The proposed design presents accepted performance for wireless applications such as S11, VSWR, gain, and radiation efficiency. The antenna operates with three resonant frequencies using only single PIN diode for frequency tuning. The experimental results show that the designed antenna can be easily fabricated and tested to maintain the measurement and then compared with the simulated one.

\section{REFERENCES}

[1] H. Schantz, "The art and science of ultrawideband antennas," Artech House, Inc, MA, 2005.

[2] G. Kumar and K. P. Ray, "Broadband microstrip antennas," Artech House, 2002.

[3] E. Erfani, J. Nourinia, C. Ghobadi, M. Niroo-Jazi, and T. A. Denidni, "Design and Implementation of an Integrated UWB/Reconfigurable-Slot Antenna for Cognitive Radio Applications," in IEEE Antennas and Wireless Propagation Letters, vol. 11, pp. 77-80, 2012, doi: 10.1109/LAWP.2011.2182631.

[4] A. I. Al-Muttairi and M. J. Farhan, "Circular polarization reconfigurable antenna based on defect ground structure for mid-band 5G applications," International Journal on Communications Antenna and Propagation, vol. 10, no. 2, pp. 114-121, 2020, doi: 10.15866/irecap.v10i2.18427.

[5] T. L. Wu, Y. M. Pan, P. F. Hu, and S. Y. Zheng, "Design of a Low Profile and Compact Omnidirectional Filtering Patch Antenna," in IEEE Access, vol. 5, pp. 1083-1089, 2017, doi: 10.1109/ACCESS.2017.2651143.

[6] J. Park, M. Jeong, N. Hussain, S. Rhee, P. Kim, and N. Kim, "Design and fabrication of triple-band folded dipole antenna for GPS/DCS/WLAN/WiMAX applications,” Microw. Opt. Technol. Lett., vol. 61, no. 5, pp. 1328-1332, February 2019, doi: https://doi.org/10.1002/mop.31739.

[7] A. K. Jassim and R. H. Thaher, "Design and analysis microstrip antenna with reflector to enhancement gain for wireless communication," Bulletin of Electrical Engineering and Informatics, vol. 9, no. 2, pp. 652-660, April 2020, doi: 10.11591/eei.v9i2.1696.

[8] Y. Zhang, W. Hong, C. Yu, Z. -Q. Kuai, Y. -D. Don, and J. -Y. Zhou, "Planar Ultrawideband Antennas with Multiple Notched Bands Based on Etched Slots on the Patch and/or Split Ring Resonators on the Feed Line," in IEEE Transactions on Antennas and Propagation, vol. 56, no. 9, pp. 3063-3068, Sept. 2008, doi: 10.1109/TAP.2008.928815.

[9] T. Dissanayake and K. P. Esselle, "Prediction of the Notch Frequency of Slot Loaded Printed UWB Antennas," in IEEE Transactions on Antennas and Propagation, vol. 55, no. 11, pp. 3320-3325, November 2007, doi: 10.1109/TAP.2007.908792.

[10] S. Nikolaou, N. D. Kingsley, G. E. Ponchak, J. Papapolymerou, and M. M. Tentzeris, "UWB Elliptical Monopoles with a Reconfigurable Band Notch Using MEMS Switches Actuated Without Bias Lines," in IEEE Transactions on Antennas and Propagation, vol. 57, no. 8, pp. 2242-2251, Aug. 2009, doi: 10.1109/TAP.2009.2024450.

[11] Y. Kim and D.-H. Kwon, "CPW-fed planar ultra wideband antenna having a frequency band notch function," Electron. Lett., vol. 40, no. 7, pp. 403-405, May 2004, doi: 10.1049/el:20040302.

[12] A. K. Jassim and R. H. Thaher, "Calculate the optimum slot area of the elliptical microstrip antenna for mobile applications," Indonesian Journal of Electrical Engineering and Computer Science, vol. 16, no. 3, pp. 1364-1370, December 2019, doi: 10.11591/ijeecs.v16.i3.pp1364-1370.

[13] Y. J. Cho, K. H. Kim, S. H. Hwang, and Seong-Ook Park, "A miniature UWB planar monopole antenna with 5 GHz band-rejection filter," The European Conference on Wireless Technology, 2005., 2005, pp. 511-514, doi: 10.1109/ECWT.2005.1617769.

[14] T. Ma, R. Hua, and C. Chou, "Design of a Multiresonator Loaded Band-Rejected Ultrawideband Planar Monopole Antenna with Controllable Notched Bandwidth," in IEEE Transactions on Antennas and Propagation, vol. 56, no. 9, pp. 2875-2883, Sept. 2008, doi: 10.1109/TAP.2008.928778.

[15] A. K. Jassim, M. J. Farhan, and A. F. Fahad, "Design selective band antenna using coupling sidewall and multi resonator for wireless communications," Bulletin of Electrical Engineering and Informatics, vol. 9, no. 5, pp. 2206-2212, October 2020, doi: 10.11591/eei.v9i5.2247. 
[16] A. A. Jabber and R. H. Thaher, "Multiband Reconfigurable MIMO Antenna for Wireless Applications," 2020 6th International Engineering Conference "Sustainable Technology and Development" (IEC), 2020, pp. 36-41, doi: 10.1109/IEC49899.2020.9122919.

[17] J. Kim, C. S. Cho, and J. W. Lee, "5.2 GHz notched ultra-wideband antenna using slot-type SRR," Electron. Lett., vol. 42, no. 6, pp. 315-316, March 2006, doi: 10.1049/el:20063713.

[18] A. A. Jabber, A. K. Jassim, and R. H. Thaher, "Compact reconfigurable PIFA antenna for wireless applications," TELKOMNIKA Telecommunication, Computing, Electronics and Control, vol. 18, no. 2, pp. 595-602, April 2020, doi: 10.12928/TELKOMNIKA.v18i2.13427.

[19] J. Liu, S. Gong, Y. Xu, X. Zhang, C. Feng, and N. Qi, "Compact printed ultra-wideband monopole antenna with dual band-notched characteristics," Electron. Lett., vol. 44, no. 12, pp. 710-711, June 2008, doi: 10.1049/el:20080931.

[20] R. Garg, P. Bhartia, I. J. Bahl, and A. Ittipiboon, "Microstrip antenna design handbook," Artech house, 2001.

[21] S. W. Lee and Y. T. Lo, “Antenna Handbook-Theory, Applications and Design Chap. 11," Van Nostrand Reinhold Co., NY, 1988.

[22] F. Di Paulo, "Networks and Devices Using Planar Transmission Lines," CRC Press LLC, Boca Raton, pp. 490-491, 2000.

[23] L. Zhu, S. Sun, and W. Menzel, "Ultra-wideband (UWB) bandpass filters using multiple-mode resonator," in IEEE Microwave and Wireless Components Letters, vol. 15, no. 11, pp. 796-798, Nov. 2005, doi: 10.1109/LMWC.2005.859011.

[24] I. G. Kiani, "Coplanar Microstrip Active Integrated Antenna for Dual Band Low Noise Amplifier," Doctoral dissertation, M. Sc Thesis, Department of Electronic Engineering. GIK Institute of Engineering Sciences and Technology, Swabi, NWFP, Pakistan, 2003.

[25] R. M. Salih, and A. K. Jassim "Microstrip patch antenna with metamaterial using superstrate technique for wireless communication" Bulletin of Electrical Engineering and Informatics, vol. 10, no. 4, August 2021, pp. 2055 2061, doi: 10.11591/eei.v10i4.2722

\section{BIOGRAPHIES OF AUTHORS}

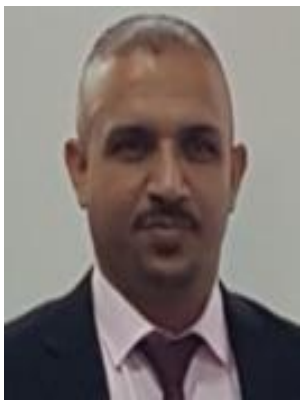

Najim Abdallah Jazea (iD SC P is Lecturer at Alhikma College University, Engineering of Computer Techniques Department. Holds a Bachelor's degree at 2004 and a Master's degree at 2011 and a Ph.D. at 2019 in communications engineering. Works in the field of cellular networks communications and antennas and has a many of research in international journals and scientific conferences. He can be contacted at email: najim.abdulah@ @iuc.edu.iq.

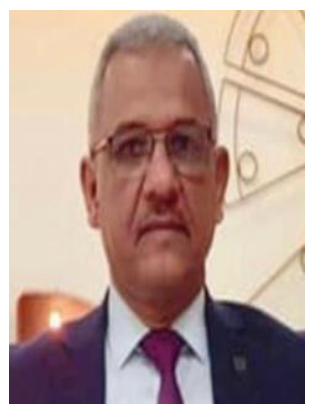

Ali Khalid Jassim (D) SC P is Lecturer at Mustansiriyah University, College of Engineering, Electrical Engineering Department. Holds a Bachelor's degree at 1999 and a Master's degree at 2010 and a Ph.D. at 2019 in Communications Engineering. Works in the field of cellular networks communications and antennas and has a many of research in international journals and scientific conferences. He can be contacted at email: alijassim@uomustansiriyah.edu.iq.

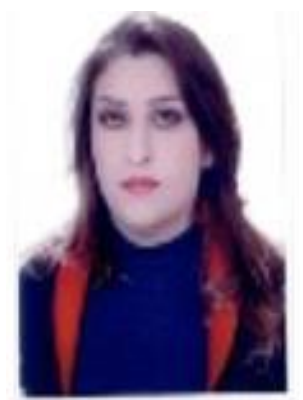

Alaa Kareem Hassan (iD $8 \mathrm{SC}$ P is Lecturer at Mustansiriyah University, College of Engineering, Electrical Engineering Department. Holds a Bachelor's degree at 1994 and a Master's degree at 2015. Works in the field of cellular networks communications and antennas and has a many of research in international journals and scientific conferences. She can be contacted at email: alaak_eng@uomustansiriyah.edu.iq. 